
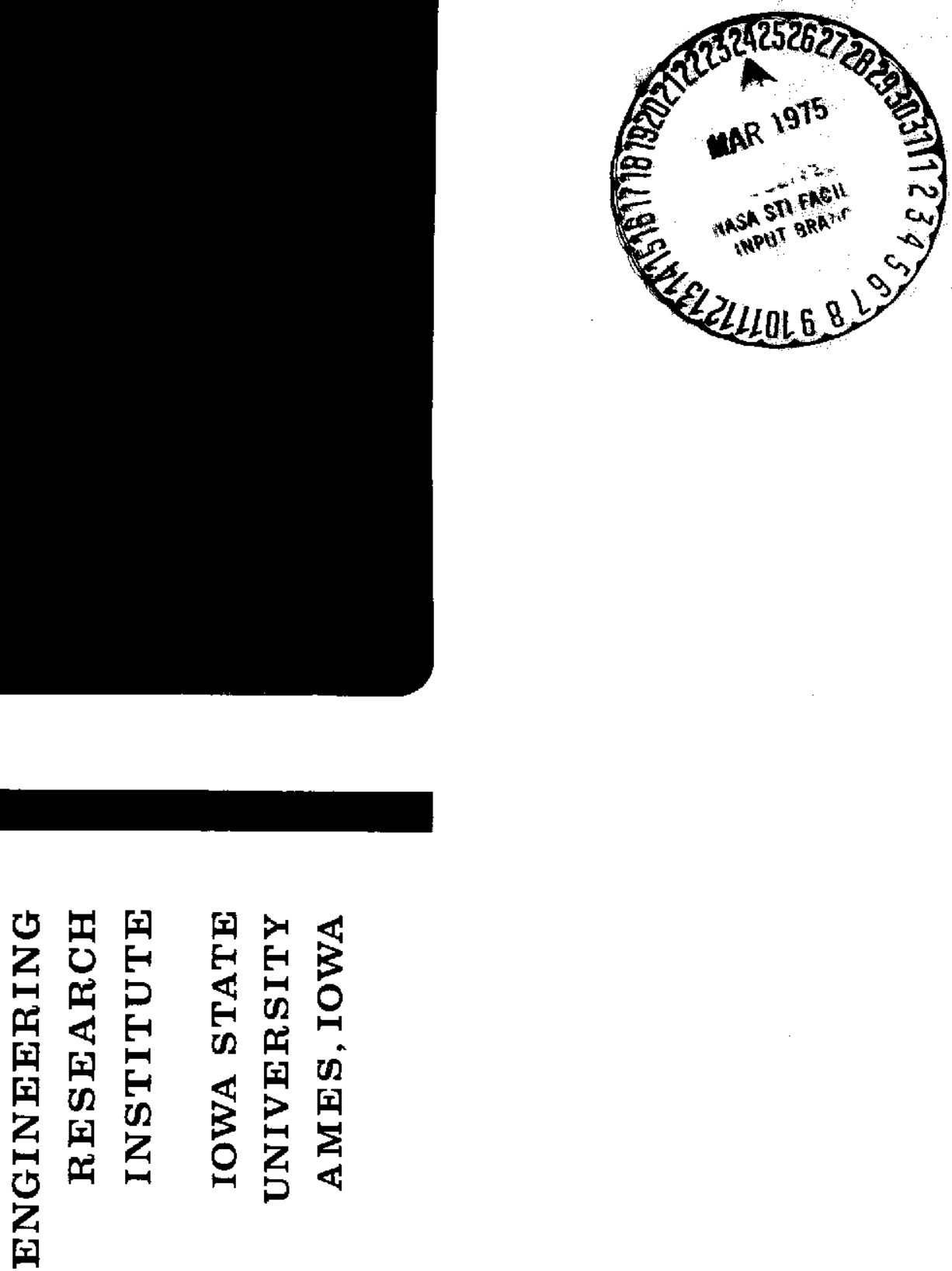
ENGINEERING

RESEARCH

ENGINEERING

RESEARCH

ENGINEERING

RESEARCH

ENGINEERING

RESEARCH

ENGINEERING

RESEARCH

TECHNICAL REPORT

\section{INVISCID TO TURBULENT TRANSITION OF TRAILING VORTICES}

James D. Iversen

November 1974

Submitted to:

National Aeronautics and Space Administration

Contract No. NGS-2040

ENGINEERING RESEARCH INSTITUTE 


\section{INTRODUCTION}

It has been discovered experimentally that a so-called "plateau" region exists in the vortex system which trails from a lifting wing. The decay of the vortex due to viscous or turbulent shear is very slow In the plateau so that the maximum tangential speed in the vortices remains very nearly constant for some distance downstream of roll-up and then begins to decrease, becoming inversely proportional to the square root of the distance far downstream.

It is possible that the delay in vortex decay, exemplified by the plateau region, is due, at least in part, to nonequilibrium turbulence in which the magnitude of turbulent shear stress takes a significant period of time to catch up with turbulent energy. It is shown here, however, that the existence of the plateau region can be explained merely by the necessity for the vortex tangential speed profile to change from an inviscid profile (inviscid except for the core) to the similarity profile far downstream. The inviscid profile is a function of span loading calculated a $\underline{1 a}$ Betz $^{2,3}$, so the extent of the plateau region is also a function of span loading.

It is assumed in the following analysis that the flow in the trailing vortex is approximately analogous to the time-dependent flow of an infinitely long vortex, so the radial and axial momentum equations are not used. This assumption usually results in good qualitative agreement in the near field just downstream of roll-up and should be close to a three-dimensional solution in the far field flow. Solutions have been obtained for both constant and vartable eddy viscosity models. 
2. VORTEX DECAY - CONSTANT EDDY VISCOSITY

The equation for an axisymmetric, infinite vortex assuming a constant eddy viscosity is

$$
\frac{\partial \gamma}{\partial t}=u_{T}\left(\frac{\partial^{2} \gamma}{\partial r^{2}}-\frac{1}{r} \frac{\partial \gamma}{\partial r}\right)
$$

To facilitate solution of this equation, the independent variables are changed:

$$
\begin{aligned}
& \tau=t / t_{0} \\
& N=r^{2} / 4 v_{T} t
\end{aligned}
$$

and the equation becomes

$$
\tau \frac{\partial \gamma}{\partial \tau}-N \frac{\partial \gamma}{\partial N}=N \frac{\partial^{2} \gamma}{\partial N^{2}}
$$

subject to the boundary conditions $\gamma\left(1, N_{0}\right)=\gamma_{i}\left(r^{2} / 4 \nu_{T} t_{0}\right), \gamma(\tau, 0)=0$, and $Y(\tau, \infty)=Y_{0}$. This is, of course, a linear differential equation solvable by separation of variables:

$$
\begin{aligned}
& Y=G(N) T(\tau) \\
& \tau \frac{d T}{d \tau}+\lambda^{2} T=0 \\
& N \frac{d^{2} G}{d N^{2}}+N \frac{d G}{d N}+\lambda^{2} G=0
\end{aligned}
$$

where $\lambda^{2}$ represents one or more constants. 
The solution to Eq. (3) is

$$
T=\sum_{i} C_{i} \tau^{-\lambda^{2}}
$$

and a solution to Eq. (4), which is a special case of Kummer's equation ${ }^{4}$, 1s given by

$$
G=-\frac{d^{\lambda^{2}-1}}{d \lambda^{2}-1}\left(N^{\lambda^{2}} e^{-N}\right)
$$

Thus, a solution of Eq. (2) which satisfies the boundary conditions is

$$
\begin{aligned}
\frac{y}{Y_{0}} & =1-e^{-N}+\sum_{\lambda^{2}=1}^{\infty} \frac{A \lambda^{2}}{T^{\lambda 2}} \frac{d^{\lambda^{2}-1}}{d N^{2}-1}\left(N^{2} e^{-N}\right) \\
& =1-e^{-N}+\frac{A_{1}}{T} N e^{-N}+\frac{A_{2}}{T^{2}}\left(2 N-N^{2}\right) e^{-N}+\text { etc. }
\end{aligned}
$$

The first two terms of this equation represent Lamb's solution for decay of an infinite line vortex.

The relationship between vortex radius and circulation for elliptic loading is given according to the Betz theory ${ }^{2}$ by

$$
r / b=\left\{\left[\pi / 8-(1 / 4) \sin ^{-1}\left(1-\tilde{\gamma}^{2}\right)^{1 / 2}\right] / \widetilde{Y}\right\}-\frac{1}{4}\left(1-\tilde{Y}^{2}\right)^{1 / 2}
$$

The variable $\mathrm{N}$ at completion of roll-up $(T=1)$ is an unknown constant times $(r / b)^{2}$. Thus, when fitting the solution Eq. (7) to the inviscid 
Eq. (8), the coefficient of $\mathrm{N}$ in the exponent must be solved for as well as the coefficlents $A_{\lambda^{2}}$. Since the resulting set of algebraic equations is nonlinear, the procedure for solving for the unknown coefficients is necessarily iterative. An example of the solution Eq. (7) for elliptic loading is

$$
\begin{aligned}
& \frac{y}{Y_{0}}=1+\mathrm{e}^{-1.6(10 \mathrm{r} / \mathrm{b})^{2} / \mathrm{T}}\left\{-1-\frac{1.5804(10 \mathrm{r} / \mathrm{b})^{2}}{\tau^{2}}\right. \\
& +\left[\frac{7.4890}{T}\left(\frac{10 \mathrm{r} / \mathrm{b}}{T}\right)^{2}-\frac{5.9912}{\left.\left(\frac{10 \mathrm{r} / \mathrm{b}}{\tau}\right)^{4}\right]}\right. \\
& +\left[\frac{-15.1114}{T^{2}}\left(\frac{10 \mathrm{r} / \mathrm{b}}{T}\right)^{2}+\frac{24.1782}{T}\left(\frac{10 \mathrm{r} / \mathrm{b}}{T}\right)^{4}-\underline{6.4475}\left(\frac{10 \mathrm{r} / \mathrm{b}}{T}\right)^{6}\right] \\
& +\left[\frac{22.6172}{\tau^{3}}\left(\frac{10 \mathrm{r} / \mathrm{b}}{\tau}\right)^{2}-\frac{54.2813}{\tau^{2}}\left(\frac{10 \mathrm{r} / \mathrm{b}}{\tau}\right)^{4}+\frac{28.9500}{\tau}\left(\frac{10 \mathrm{r} / \mathrm{b}}{\tau}\right)^{6}\right. \\
& \left.-3.8600\left(\frac{10 \mathrm{r} / \mathrm{b}}{\tau}\right)^{8}\right]+\left[\frac{-18.2540}{\tau^{4}}\left(\frac{10 \mathrm{r} / \mathrm{b}}{\tau}\right)^{2}+\frac{58.4129}{\tau^{3}}\left(\frac{10 \mathrm{r} / \mathrm{b}}{\tau}\right)^{4}\right. \\
& \left.-\frac{46.7302}{\tau^{2}}\left(\frac{10 \mathrm{r} / \mathrm{b}}{\tau}\right)^{6}+\frac{12.4614}{\tau}\left(\frac{10 \mathrm{r} / \mathrm{b}}{\tau}\right)^{8}-0.9969\left(\frac{10 \mathrm{r} / \mathrm{b}}{\tau}\right)^{10}\right] \\
& +\left[\frac{7.4438}{T^{5}}\left(\frac{10 \mathrm{r} / \mathrm{b}}{T}\right)^{2}-\frac{29.7751}{T^{4}}\left(\frac{10 \mathrm{r} / \mathrm{b}}{\tau}\right)^{4}+\frac{31.7601}{\tau^{3}}\left(\frac{10 \mathrm{r} / \mathrm{b}}{T}\right)^{6}\right. \\
& \left.\left.-\frac{12.7035}{\tau^{2}}\left(\frac{10 \mathrm{r} / \mathrm{b}}{\tau}\right)^{8}+\frac{2.0326}{\tau}\left(\frac{10 \mathrm{r} / \mathrm{b}}{\tau}\right)^{10}-0.1084\left(\frac{10 \mathrm{r} / \mathrm{b}}{\tau}\right)^{12}\right]\right\}
\end{aligned}
$$


This equation fits the inviscid solution fairly well, as shown in Fig. 1, except for the viscous core region. That the actual experimental profile corresponds to the inviscid Betz solution (except for the viscous core) has been shown to be true by Rossow ${ }^{5}$.

A previous solution for a constant viscosity, non-potential vortex was obtained by Kirde ${ }^{6}$. He obtained a solution involving confluent hypergeometric functions for which the initial tangential velocity varies as $\mathrm{r}^{-1 / 2}$, as does the inviscid Betz solution for smal1 radius for elliptic loading. However, Kirde's solution is not valid for large radius as the circulation in his initial vortex varies as $r^{1 / 2}$ for large $r$ rather than approaching a constant value as does the solution Eq. (9).

The tangential velocity profiles in the vortex for various values of time following roll-up $(\Delta \tau=\tau-1)$ are shown in Fig. 2. For large values of time $\Delta T$, the profile approaches the Lamb solution. The maximum tangential speed as a function of time (or downstream distance) is shown in Fig. 3, along with experimental data from water channel, wind tunne1, and flight tests. For low Reynolds number, the distance data has been modified by a function of Reynolds number, as described in Ref. 7. A1though the constant viscosity assumption results in a profile that does not match experiment far downstream, stil1 the maximum velocity curve seems to match the data very well, showing both the near field plateau and the simflarity decay region far downstream. Thus, although nonequilibrium turbulence may have a hand in shaping the plateau region, it has been shown here that the existence of the plateau can be attributed at least primarily to the adfustment of the vortex profile from the inviscid to the viscous similar solution.

Solutions for constant eddy viscosity were also obtained for two other span loadings. The circulation profile for triangular loading, for which 


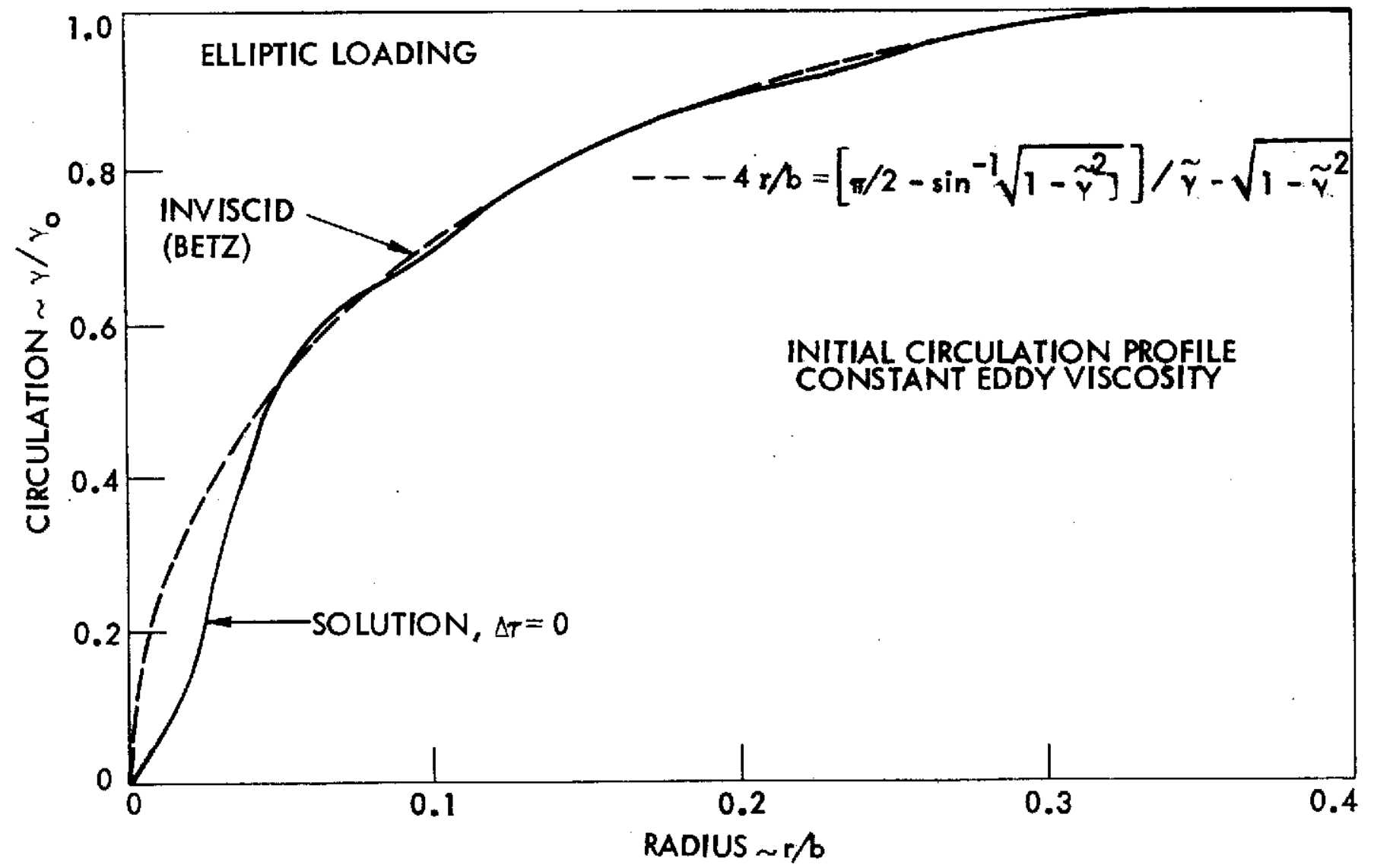

Fig. 1. Initial circulation profile, elliptic loading. 


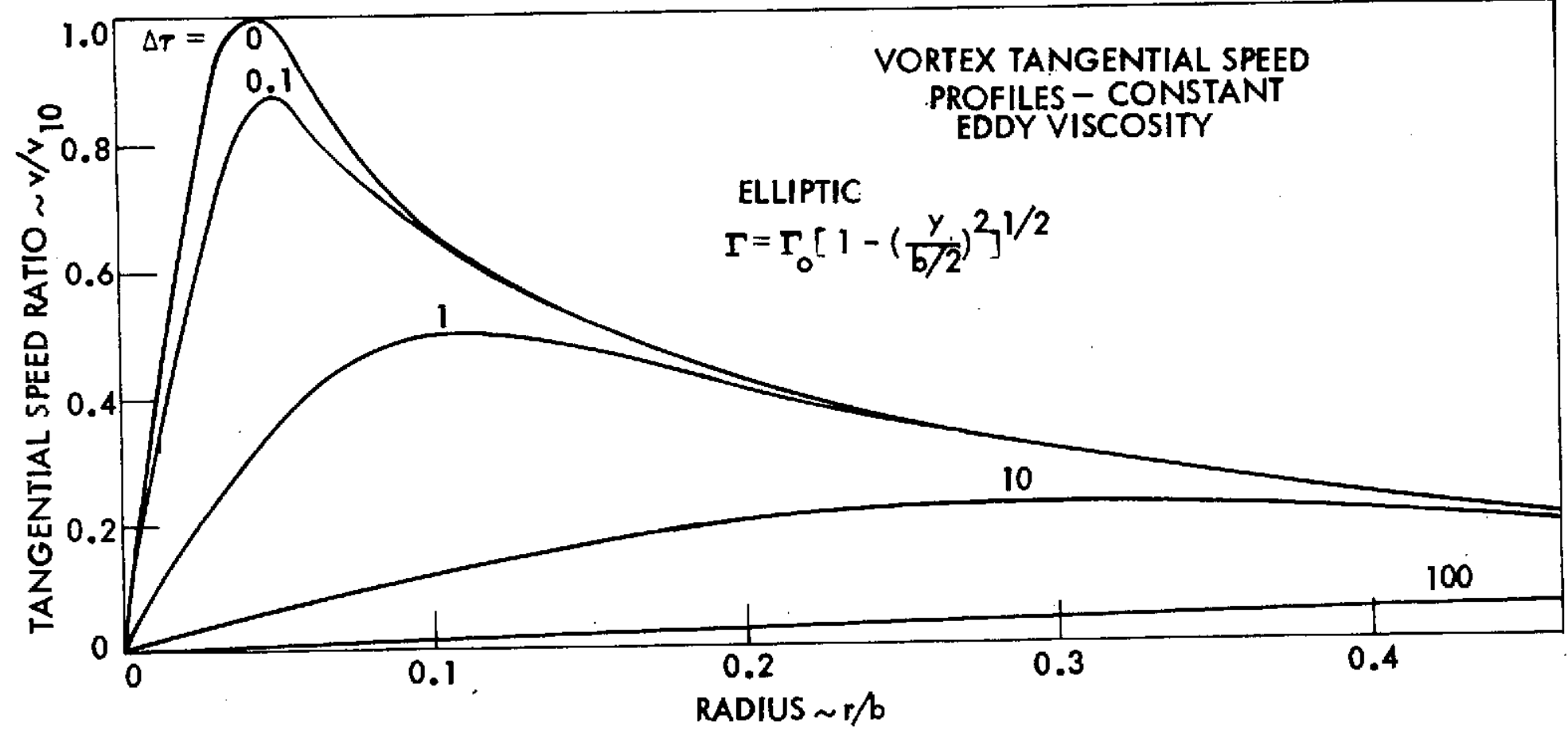

Fig. 2. Tangential speed profiles as a function of time, elliptic loading. 




Fig. 3. Maximum tangential speed vs. downstream distance, elliptic loading. 
the inviscid solution is given by

$$
\widetilde{\gamma}=4 \mathrm{r} / \mathrm{b}, \mathrm{r} / \mathrm{b}<0.25
$$

is shown in Fig. 4. The solution of Eq. (2) in this case is

$$
\begin{aligned}
& \widetilde{Y}=1+e^{-1.6(10 \mathrm{r} / \mathrm{b})^{2 / \tau}}\left[-1+1.6(10 \mathrm{r} / \mathrm{b})^{2}\left\{-\frac{2.4317}{\tau^{2}}+\frac{5.2262}{\tau^{3}}\right.\right. \\
& \left.-\frac{6.0462}{\tau^{4}}+\frac{4.16664}{\tau^{5}}-\frac{1.40244}{\tau^{6}}+\frac{0.42408}{\tau^{7}}\right\}+(1.6)^{2}(10 \mathrm{r} / \mathrm{b})^{4}\left\{-\frac{2.6131}{\tau^{4}}\right. \\
& \left.+\frac{6.0462}{\tau^{5}}-\frac{6.24996}{\tau^{6}}+\frac{2.80488}{\tau^{7}}-\frac{1.0602}{\tau^{8}}\right\}+(1.6)^{3}(10 \mathrm{r} / \mathrm{b})^{6}\left\{-\frac{1.0077}{\tau^{6}}\right. \\
& \left.+\frac{2.08332}{\tau^{7}}-\frac{1.40244}{\tau^{8}}+\frac{0.7068}{T^{9}}\right\}+(1.6)^{4}(10 \mathrm{r} / \mathrm{b})^{8}\left\{-\frac{0.17361}{T^{8}}\right. \\
& \left.+\frac{0.23374}{\tau^{9}}-\frac{0.1767}{\tau^{10}}\right\}+(1.6)^{5}(10 \mathrm{r} / \mathrm{b})^{10}\left\{-\frac{0.011687}{\tau^{10}}+\frac{0.01767}{\tau^{11}}\right\} \\
& \left.+(1.6)^{6}(10 \mathrm{r} / \mathrm{b})^{12}\left\{-\frac{0.000589}{T^{12}}\right\}\right]
\end{aligned}
$$

The velocity profiles corresponding to Eq. (11) are shown in Fig. 5. For a span loading such that

$$
\tilde{Y}=\left[1-(2 y / b)^{2}\right]^{3}
$$




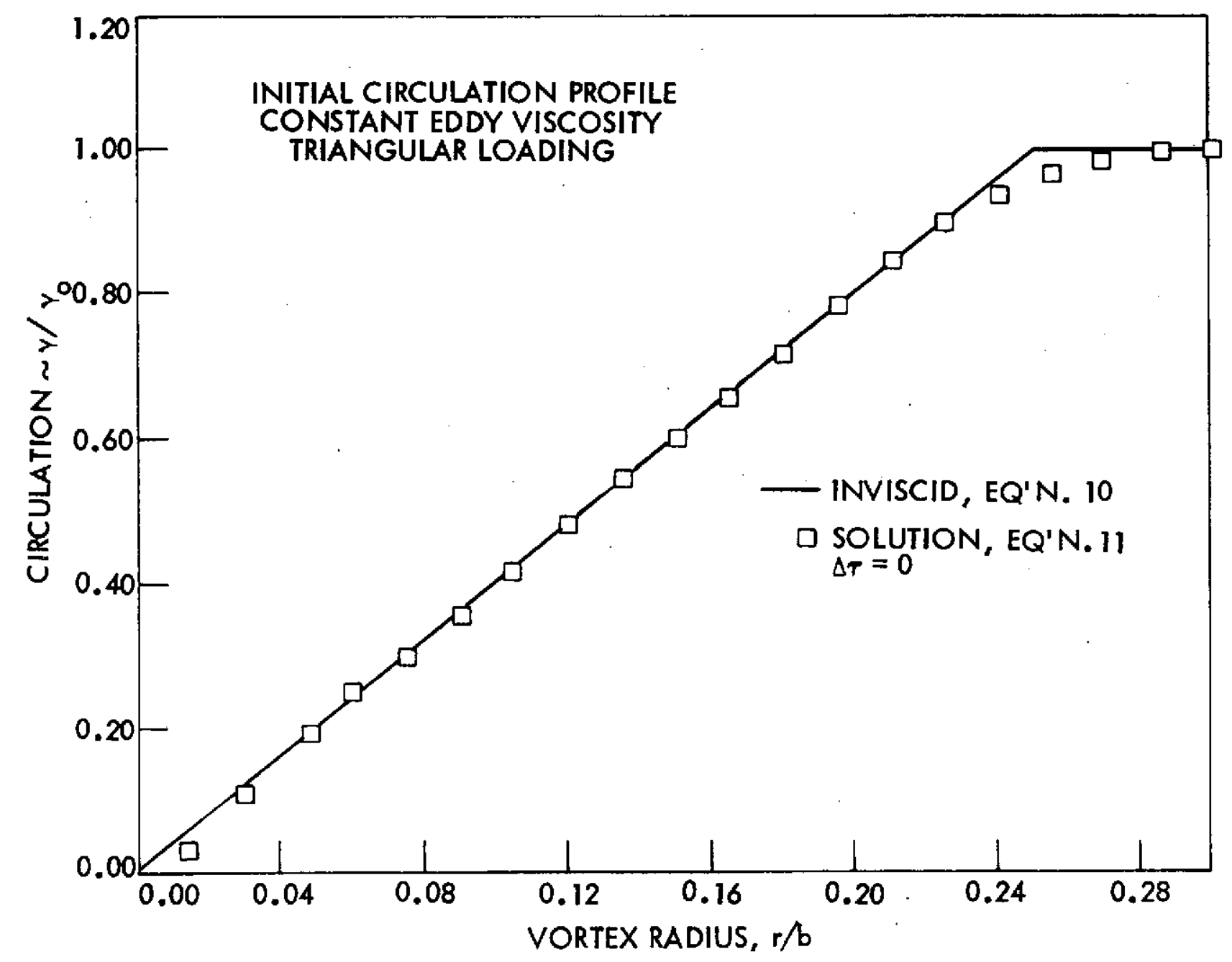

Fig. 4. Inttial circulation profile, triangular loading. 


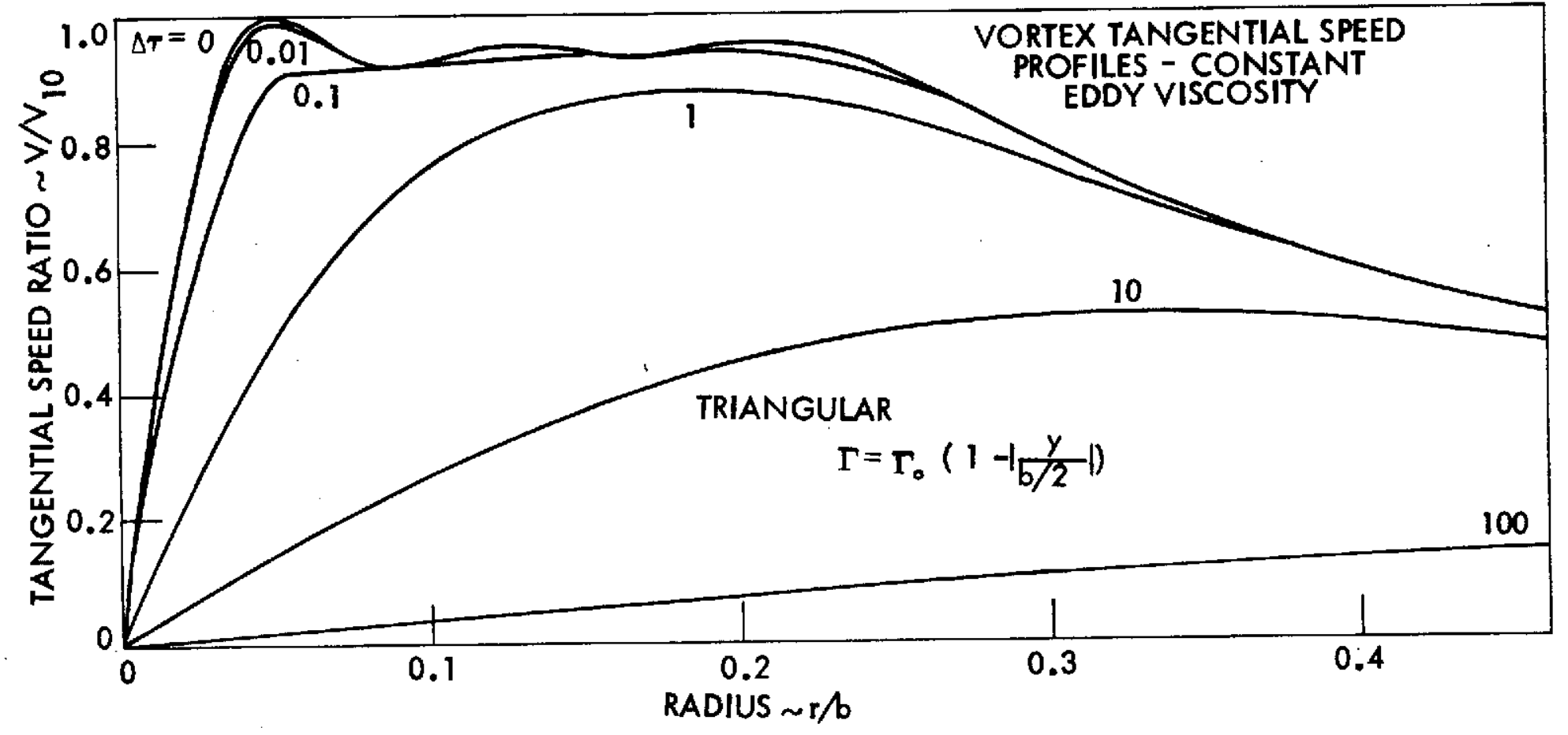

Fig. 5. Tangential speed profiles as a function of time, triangular loading. 


$$
\begin{aligned}
& \widetilde{Y}=1+e^{-1.6(10 \mathrm{r} / \mathrm{b})^{2 / \tau}}\left\{-1+1.6(10 \mathrm{r} / \mathrm{b}){ }^{2}\left[-\frac{0.58294}{\tau^{2}}+\frac{-0.2961}{\tau^{3}}\right.\right. \\
& \left.+\frac{1.7457}{T^{4}}-\frac{2.90808}{T^{5}}+\frac{2.33412}{T^{6}}-\frac{0.8496}{T^{7}}\right]+(1.6)^{2}(10 \mathrm{r} / \mathrm{b})^{4}\left[\frac{0.14805}{T^{4}}\right. \\
& \left.-\frac{1.7457}{T^{5}}+\frac{4.36212}{T^{6}}-\frac{4.66824}{T^{7}}+\frac{2.124}{T^{8}}\right]+(1.6)^{3}(10 \mathrm{r} / \mathrm{b})^{6}\left[\frac{0.29095}{T^{6}}\right. \\
& \left.-\frac{1.45404}{\tau^{7}}+\frac{2.33412}{\tau^{8}}-\frac{1.416}{\tau^{9}}\right]+(1.6)^{4}(10 \mathrm{r} / \mathrm{b})^{8}\left[\frac{0.12117}{\tau^{8}}-\frac{0.38902}{\tau^{9}}\right. \\
& \left.+\frac{3.54}{\tau^{10}}\right]+(1.6)^{5}(10 \mathrm{r} / \mathrm{b})^{10}\left[\frac{0.019451}{10}-\frac{0.0354}{\tau_{T}^{11}}\right] \\
& \left.+(1.6)^{6}(10 \mathrm{r} / \mathrm{b})^{12}\left[\frac{0.00118}{\tau^{12}}\right]\right\}
\end{aligned}
$$

The circulation and velocity profiles for this case are depicted in Figs. 6 and 7 , respectively.

The effect of span loading on the initial maximum tangential velocity level and duration of the plateau is shown in Fig. 8. The triangular loading results in a maximum tangential speed immediately after rol1-up which is less than half that for elliptic loading. This result has also been shown experimentally ${ }^{1}$. Thus, the hazard to trailing aircraft would be reduced for generating aircraft which exhibit this type of span loading. Far downstream, the solutions merge and the hazard far downstream, which is less than in the plateau, becomes independent of span loading. 


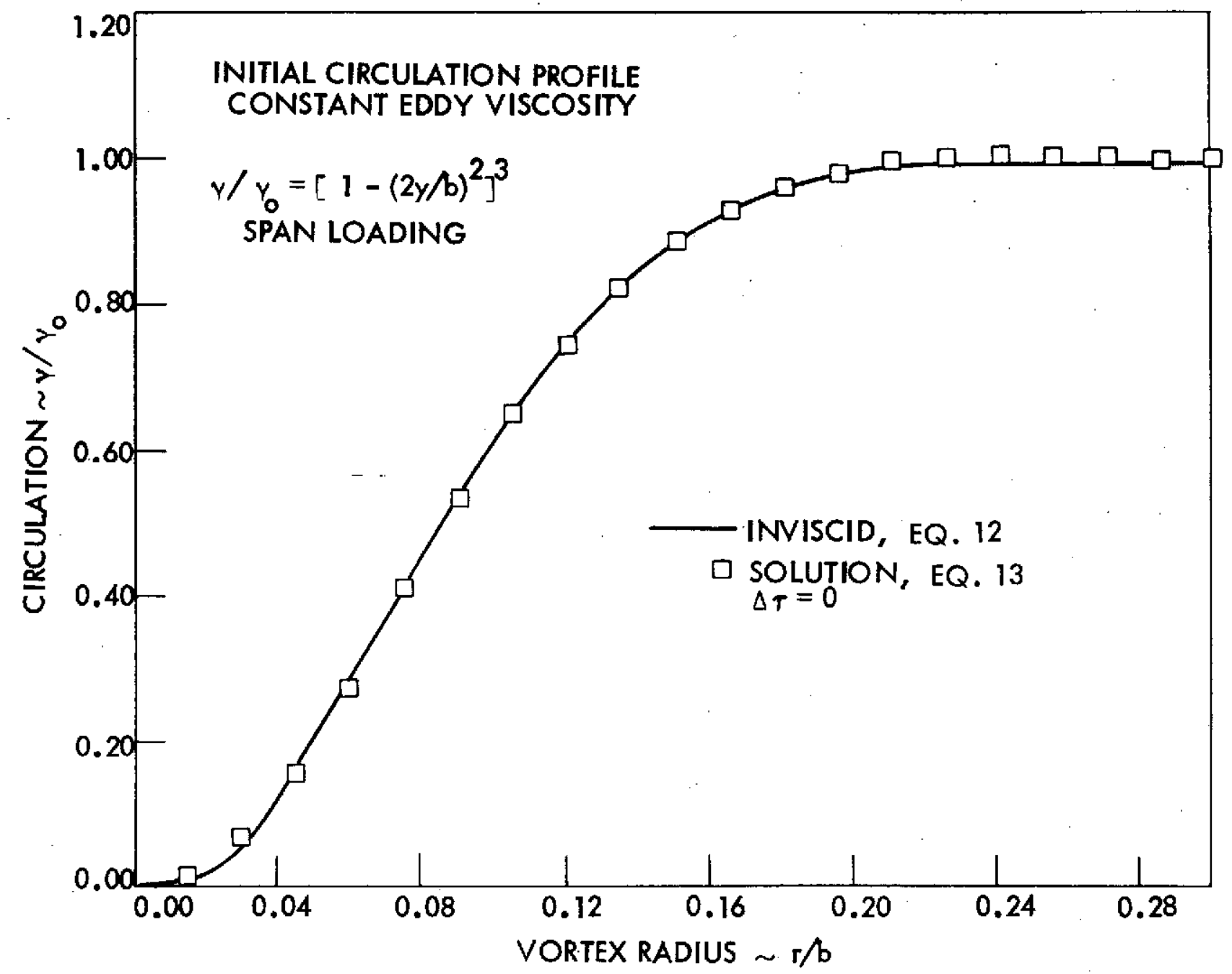

Fig. 6. Initial circulation profile, intermediate loading. 


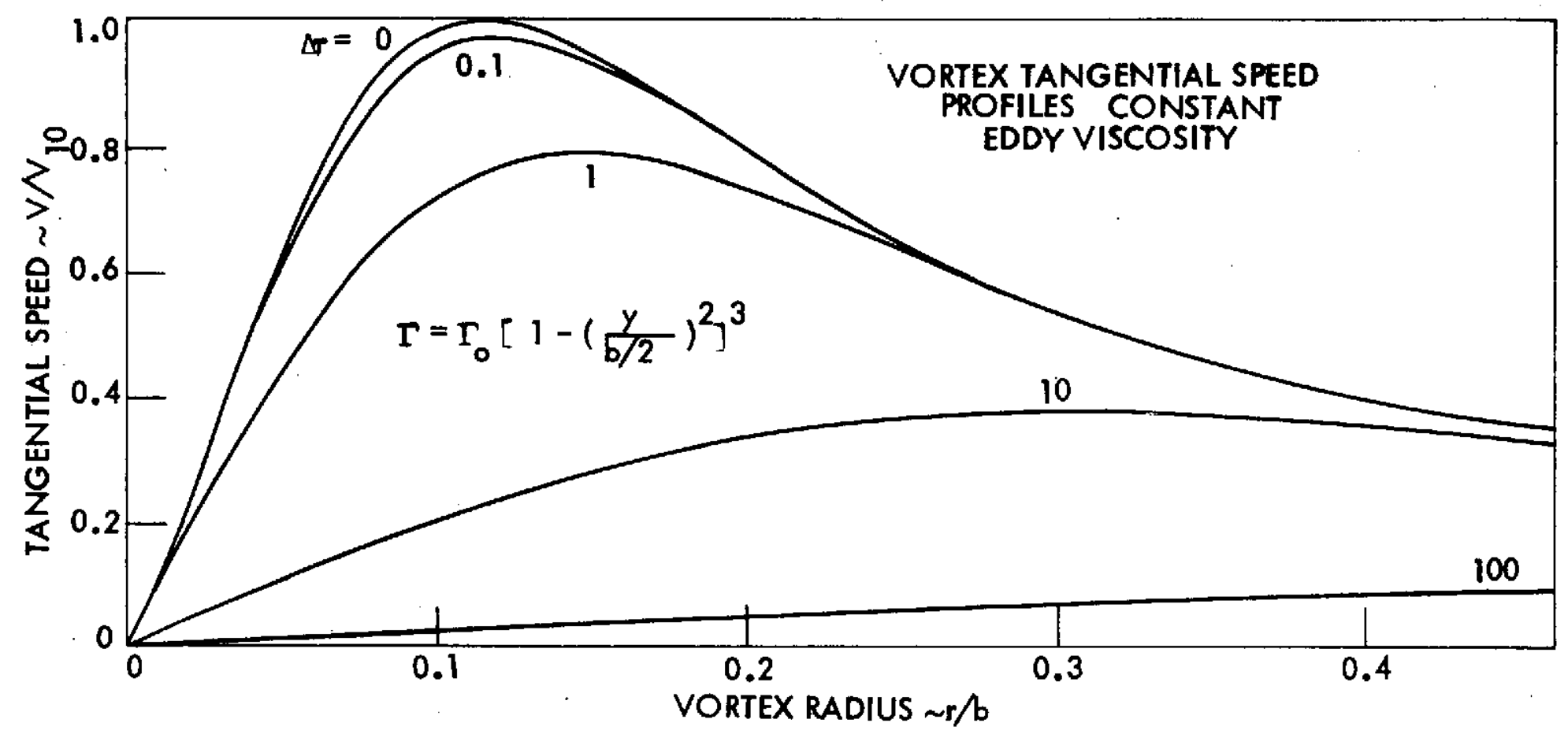

F1g. 7. Tangential speed profiles as a function of time, intermediate loading. 


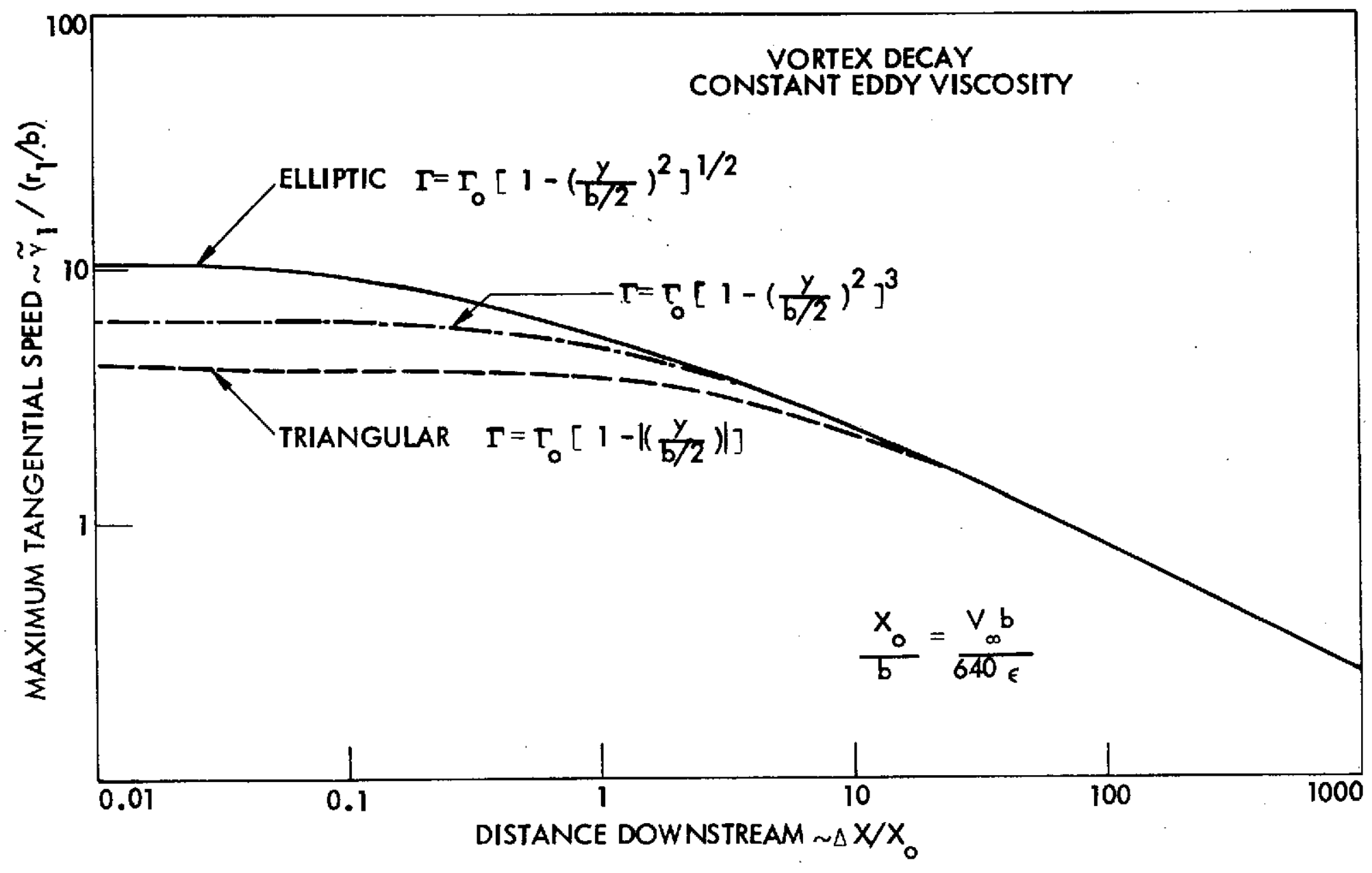

Fig. 8. Maximum tangential speed vs, downstream distance, loading comparison. 


\section{VORTEX DECAY - VARIABLE EDDY VISCOSITY}

As in Ref. 7, in order to simulate the variation of turbulent shear stress with vortex radius, the eddy viscosity is approximated, using the mixing length concept, as

$$
\nu_{\mathrm{T}}=\alpha^{2} \mathrm{r}^{2}\left|\mathrm{r} \frac{\partial}{\partial \mathrm{r}}\left(\frac{y^{2}}{r^{2}}\right)\right|
$$

With this eddy viscosity model and changing variables from $t, r$ to $T=t / t_{0}$, and $N=r^{2} / 4 \alpha^{2} Y_{0} t$, Eq. (3) of Ref. 7 becomes

$$
\tau \frac{\partial \tilde{\gamma}}{\partial \tau}=\left\{4\left|\mathrm{~N} \frac{\partial \tilde{\gamma}}{\partial N}-\tilde{\gamma}\right|+\nu / \alpha^{2} \gamma_{0}\right\} N \frac{\partial^{2} \tilde{\gamma}}{\partial N^{2}}+N \frac{\partial \tilde{\gamma}}{\partial N}
$$

Equation (15) was solved using a Crank-Nicholson finite difference scheme. The velocity profiles for a vortex trailing from an elliptically loaded wing for various times following roll-up are shown in Fig. 9. Figure 10 illustrates the maximum tangential speed in the vortex as a function of time or downstream distance. Because of the fact that the Inftial profile [Eq. (8)] was completely inviscid in this case, the plateau does not appear, and the initial decay in the vortex is approximately $\Delta x^{-1 / 3}$, substantiating C. E. Brown's theory ${ }^{8}$ for elliptic span load profiles. Far downstream, however, the effect of span load gradually disappears, and the maximum tangential speed eventually decays as $\Delta \mathrm{x}^{-1 / 2}$, as shown.

Also shown in Fig. 10 are the results of a calculation in which the initial inviscid profile was modified to incorporate solid body rotation 


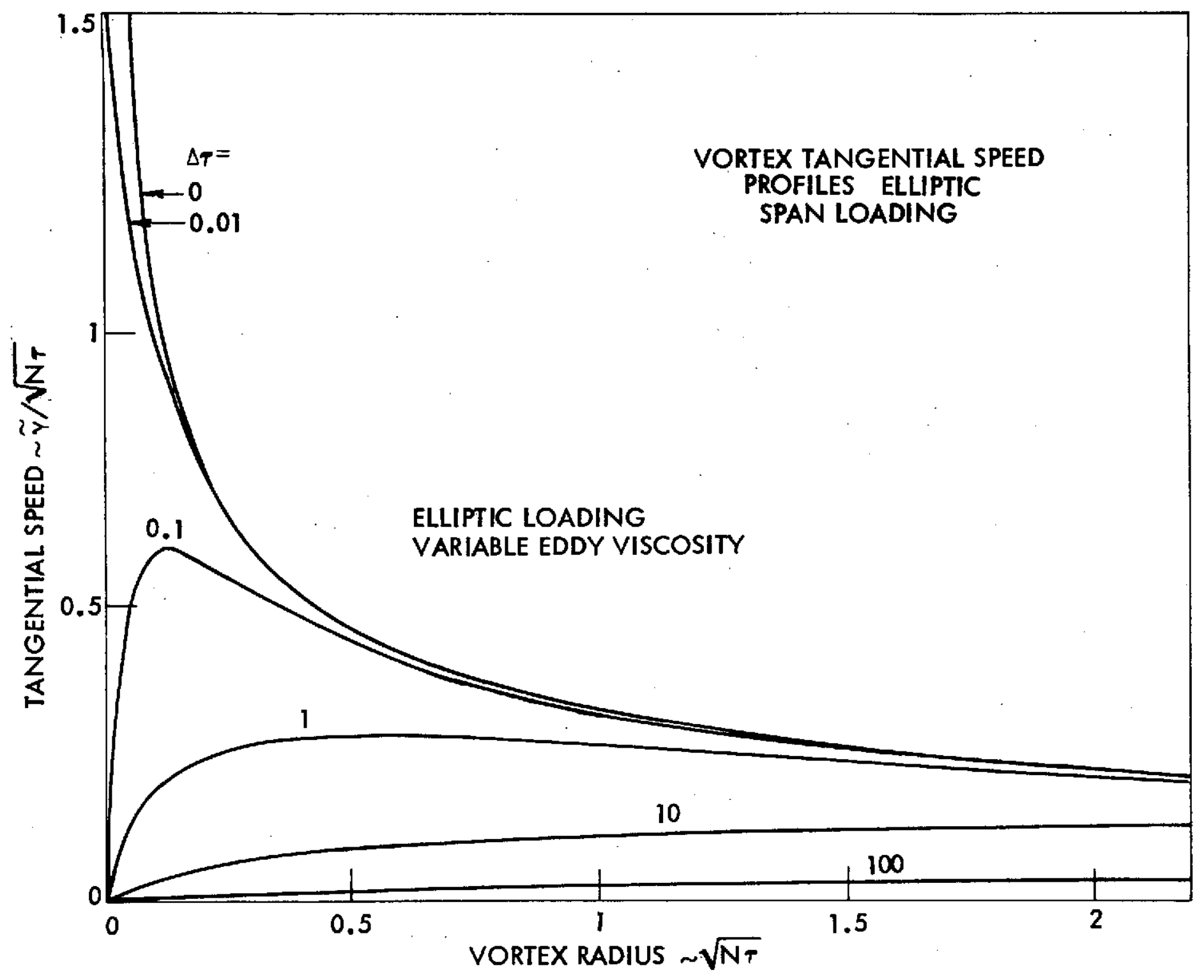

Fig. 9. Tangential speed profiles as a function of time, elliptic loading, variable eddy viscosity. 


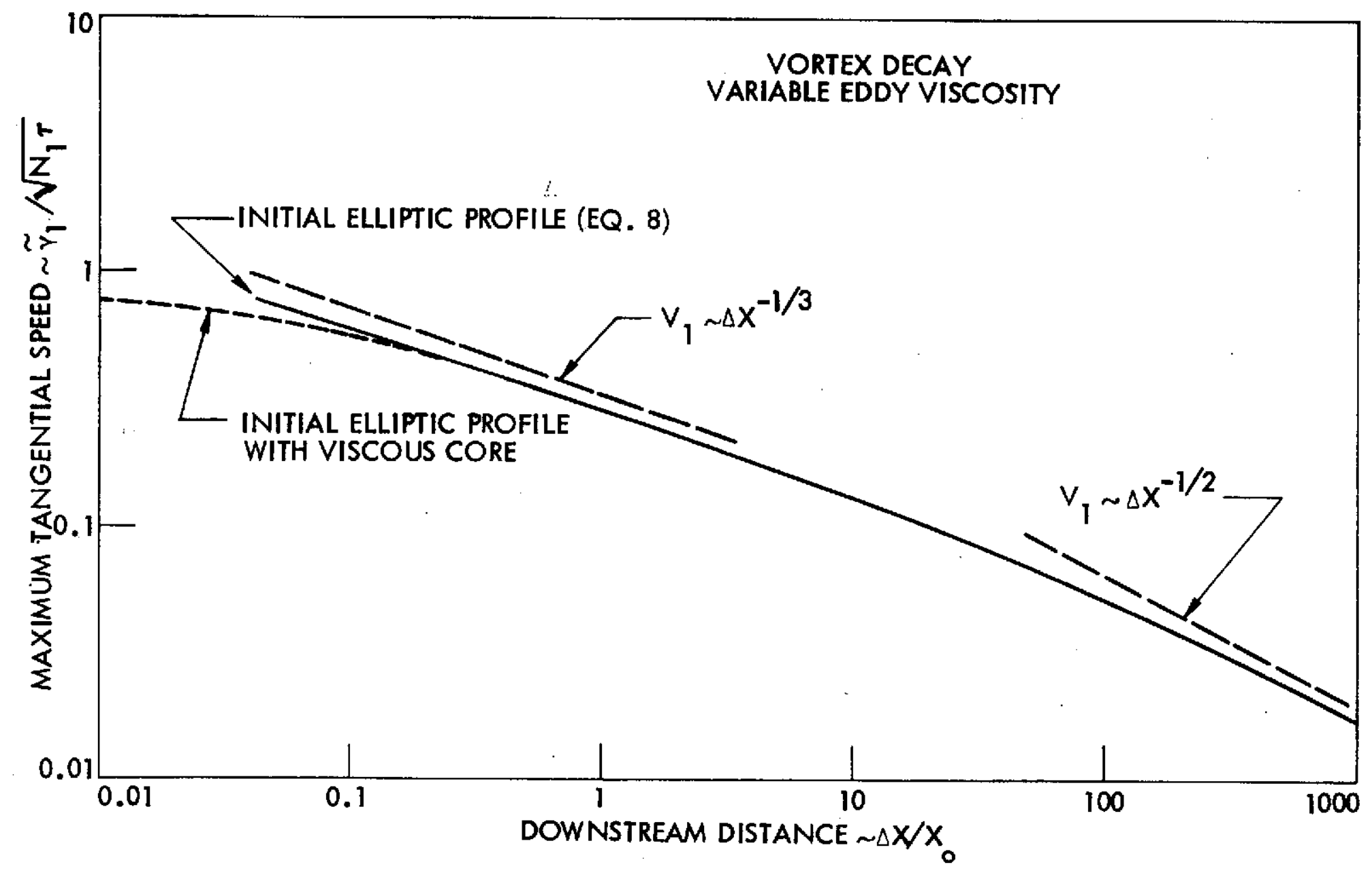

Fig. 10. Maximm tangential speed vs. downstream distance, elliptic loading, varlable eddy viscosity. 
in the core (illustrated in Fig. 11). For this example, the core radius chosen is quite small so the extent of the plateau is short. The end of the plateau region is Illustrated by the dotted line in Fig. 10 . Experimental data for approximately elliptic span loads (Fig. 3) show relatively larger core sizes, a longer plateau, and a very much shorter region in which the maximum speed varies as $\Delta \mathrm{x}^{-1 / 3}$.

Velocity profiles for a triangular span loading [Eq. (10)] are 11lustrated for various distances downstream in Fig. 12. The inviscid Betz solution for this case results in a tangential speed which is constant from the center of the vortex out to one-fourth the span. Viscosity and turbulent shear quickly round the corners of the initial profile, but the maximum tangential speed stays nearly constant out to $\Delta_{T}=0.5$, as shown in Fig. 13 by the extensive plateau. Similarity and the $\Delta \mathrm{X}^{-1 / 2}$ decay follow the plateau very quickly, in contrast to Fig. 10 and in harmony with the data of Ref. 1 .

Figures 14 and 15 exhibit the core radius and circulation values as functions of downstream distance for the three calculated cases. The existence and relative extent of the plateau is also clearly shown by the elliptic viscous core and triangular loading curves for core radius in Fig. 14. The core radius for the inviscid elliptic case initially grows as $\Delta \mathrm{x}^{0.6}$, which is slightly different from Brown's expectation of $\Delta \mathrm{x}^{2 / 3}$. The difference is probably due to the fact that the profile shape continua1ly changes and therefore does not satisfy. the criterion of similarity. Far downstream the radius grows as $\Delta x^{1 / 2}$. The difference in core radius circulation between elliptic and triangular span loading as evidenced in Fig. 15 is striking. The circulation ratio, $\Gamma_{1} / \Gamma_{0}$, for the elliptic case would increase in the plateau region with increase in 


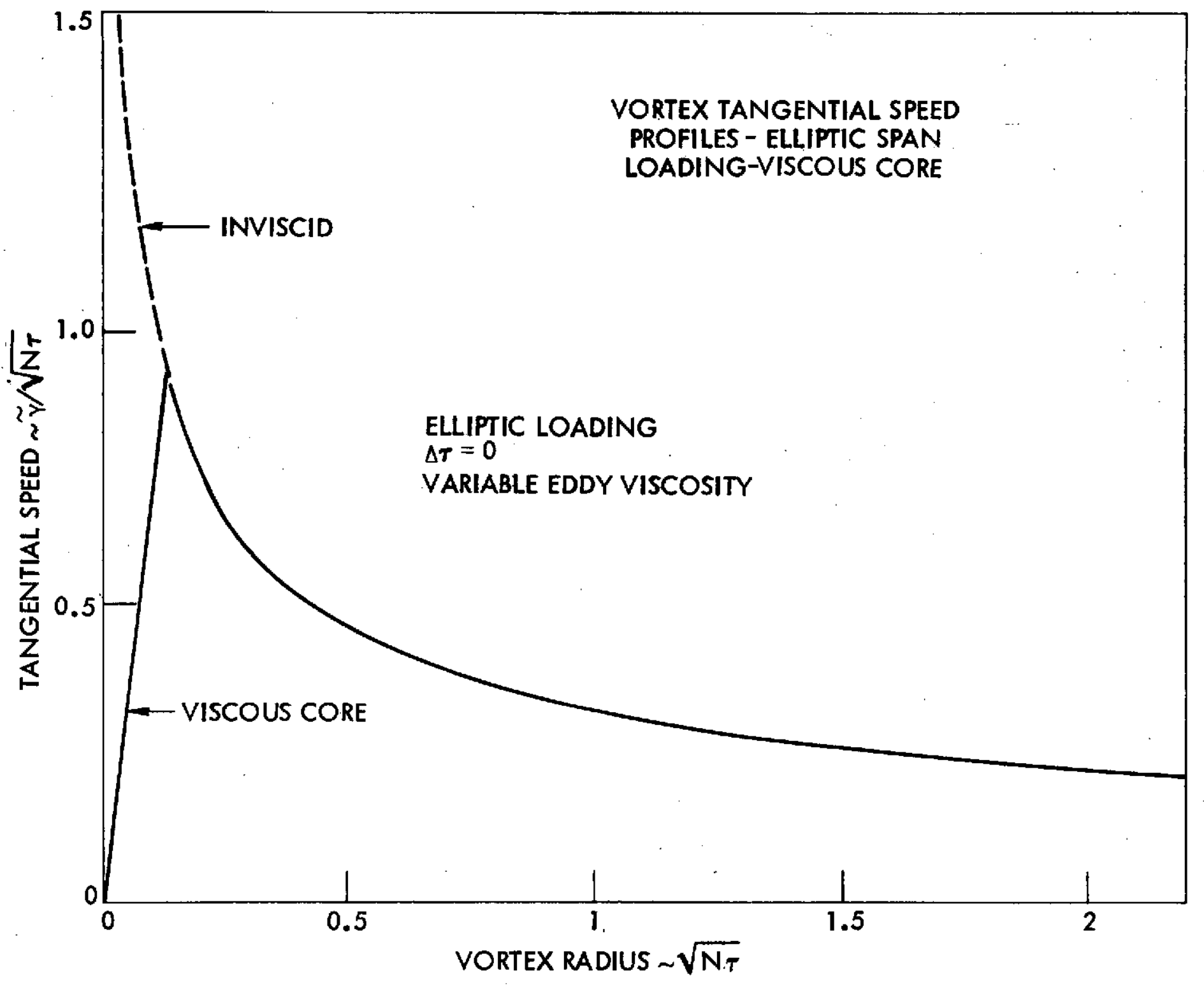

Fig. 11. Initial tangential speed profile, elliptic loading. 


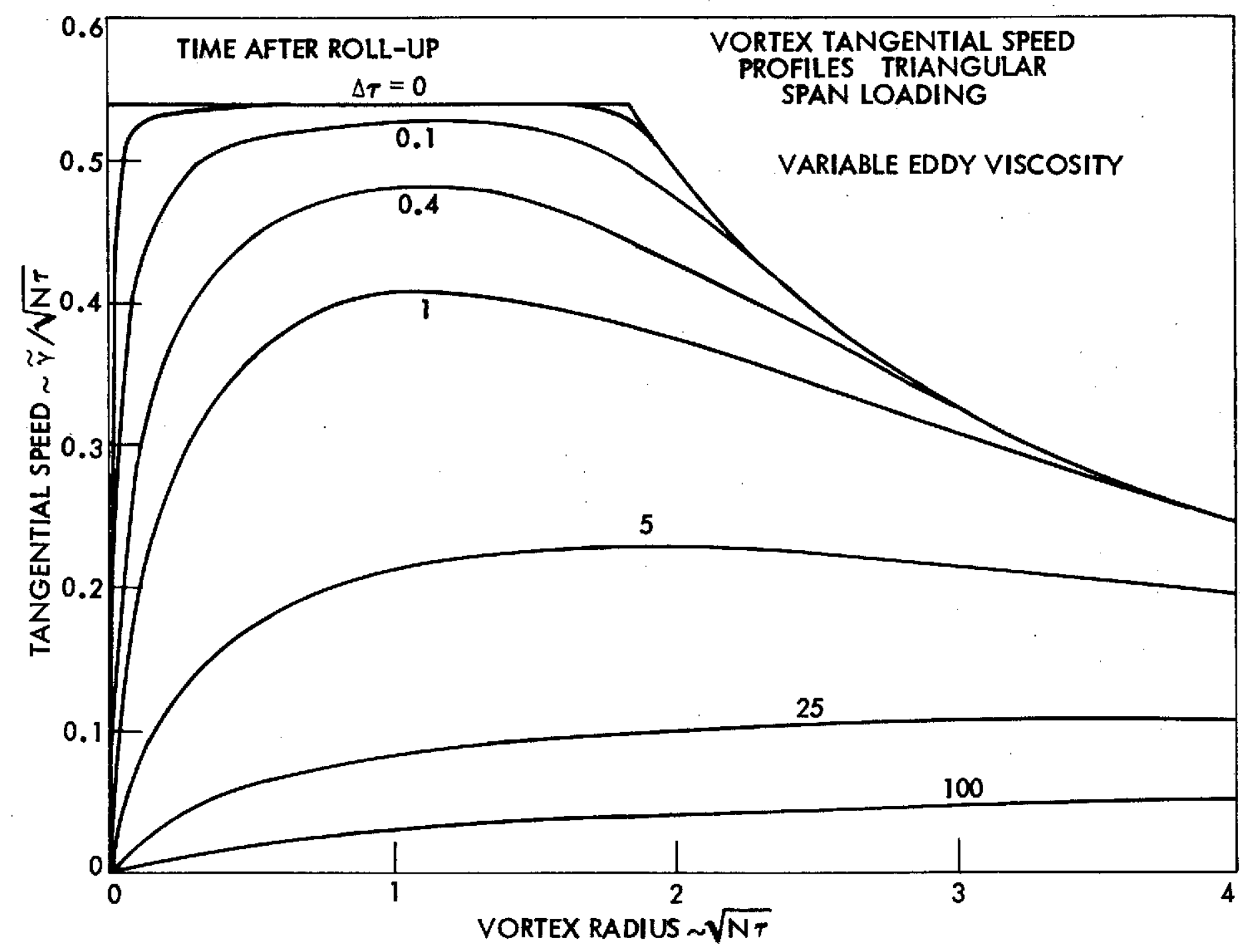

Fig. 12. Tangential speed profiles as a function of time, triangular loading, variable eddy viscosity. 


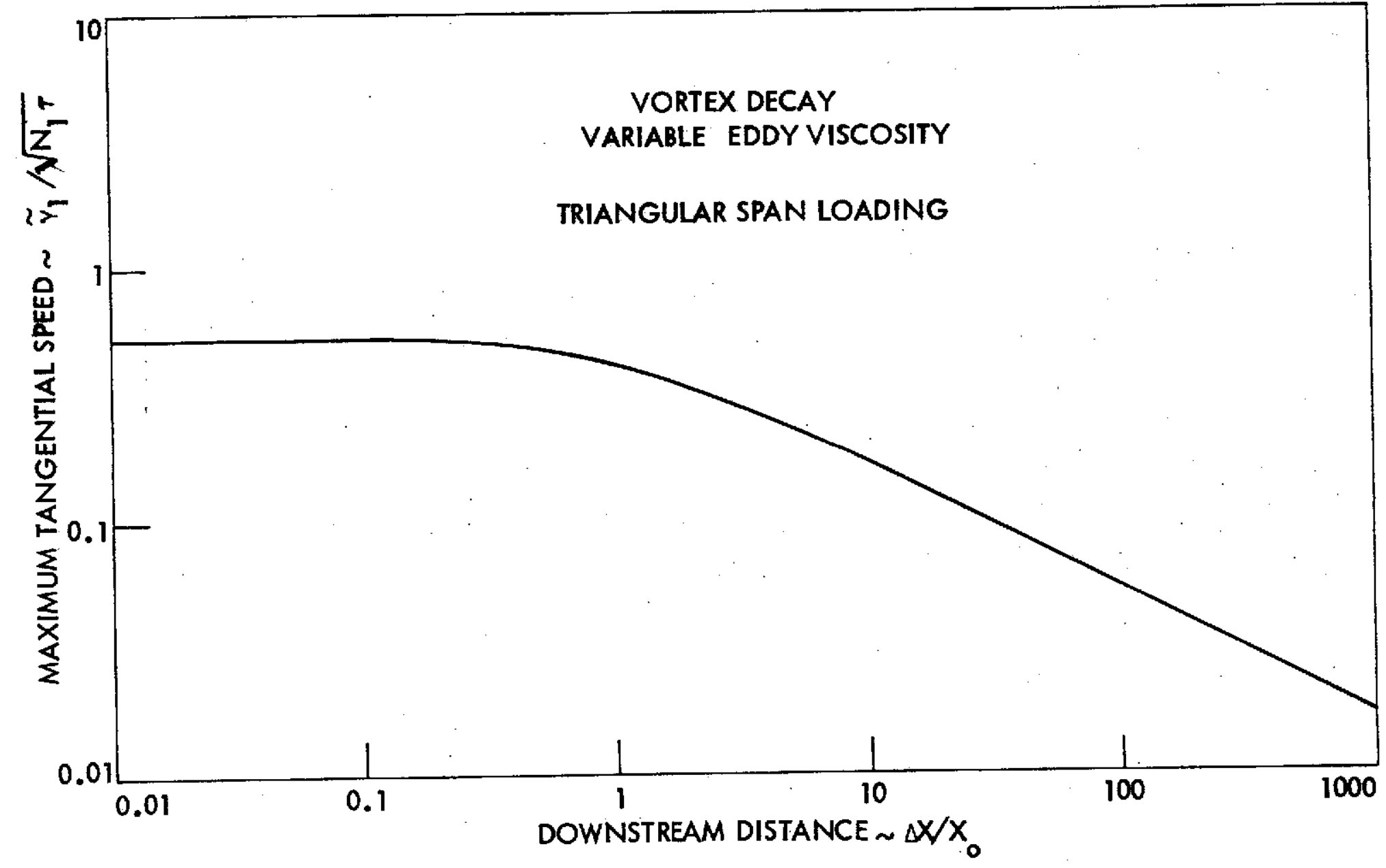

Fig. 13. Maximum tangential speed vs. downstream distance, triangular loading, variable eddy viscosity. 


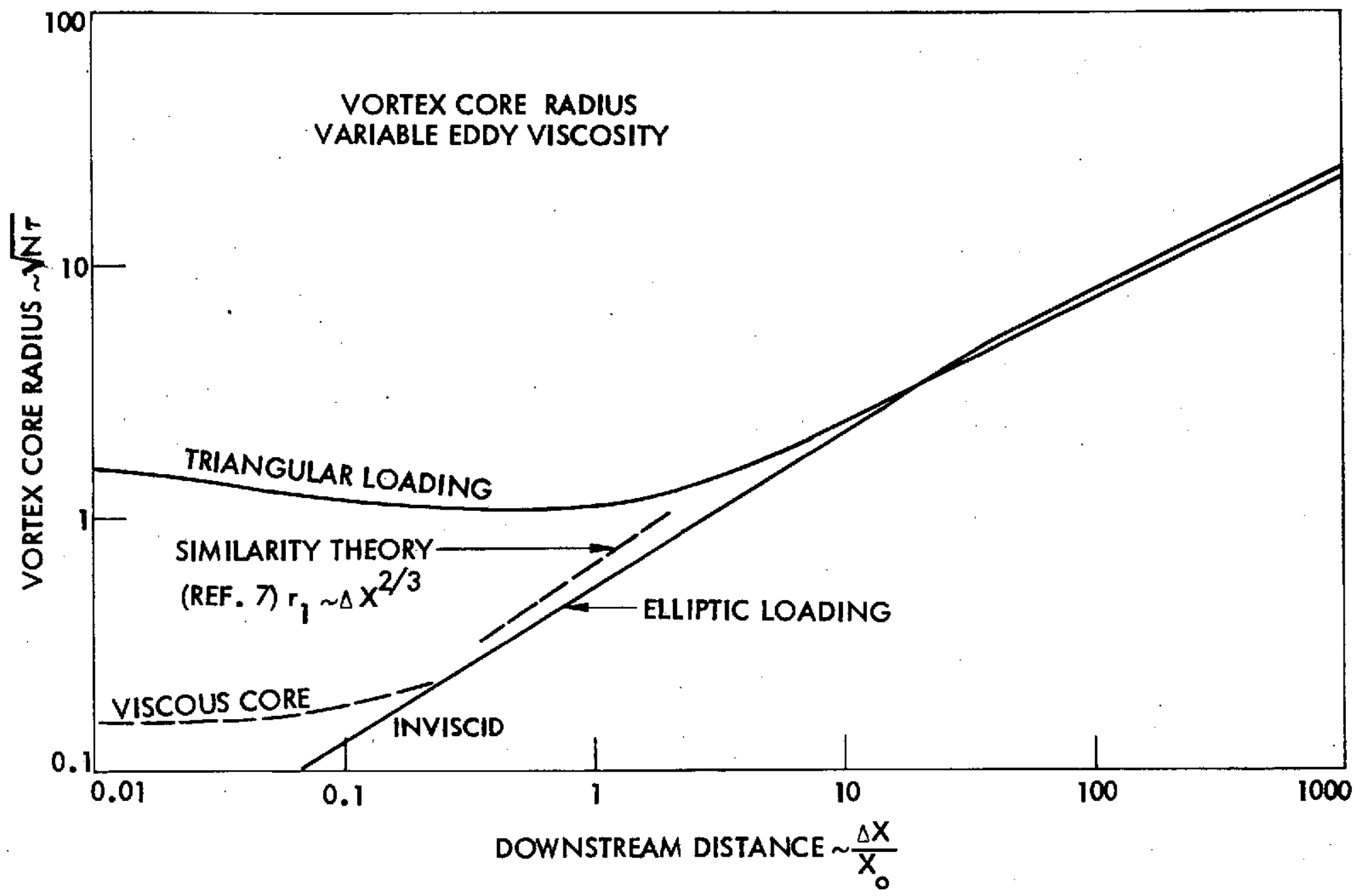

$\tilde{\omega}$

Fig. 14. Vortex core radius vs. downstream distance, loading comparison, variable eddy viscosity. 


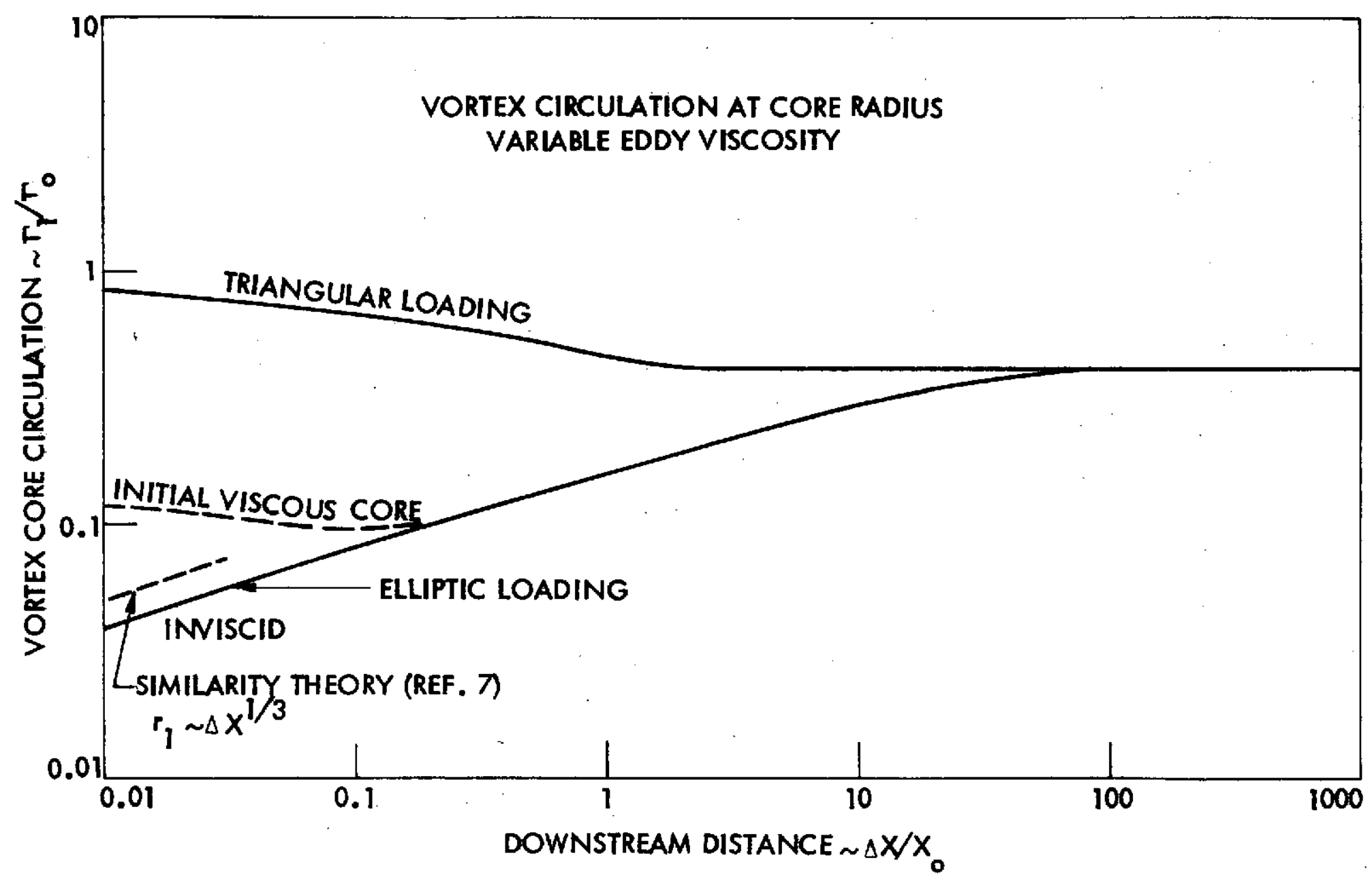

Fig. 15. Core radius circulation vs. downstream distance, loading comparison, variable eddy viscosity. 
initial core size, but would usually be less than the far downstream value of 0.41 which results from the turbulent eddy viscosity model used here. The effect of the span loading in the near field and of variable eddy viscosity in the far field is to keep the value of core radius circulation far below that predicted by the Lamb solution for a potential vortex $\left(\Gamma_{1} / \Gamma_{0}=0.715\right)$. Therefore, previous reports ${ }^{9}$ of puzzlingly low values of circulation ratio are easily explained.

\section{CONCLUSIONS}

The existence of a plateau region in which the trailing vortices exhibit a very slow decay of maximum tangential speed has been verified by the use of both constant and variable eddy viscosity models. While the shape of the plateau is probably influenced by the effects of axial flow and nonequilibrium turbulence, it has been shown that the existence of the plateau can be explained by the presence of the viscous core and by the necessity for the initial, nearly inviscid tangential velocity profile to undergo transformation to a turbulent similarity profile far downstream.

Variation in span loading is shown to affect the initial maximum tangential speed in the vortex as well as the duration of the plateau. Triangular span loading would reduce the hazard to trailing aircraft from that due to more conventional loading since the initial tangential speed is much lower. This can be explained by the fact that the inviscid profile for triangular loading exhibits a finite tangential speed at the vortex centerline and an extensive plateau results even without an initial solid body core. Elliptic span loading, however, results in an inviscid 
profile having an infinite speed at the centerline of the vortex, and a viscous core is thus necessary for the existence of a plateau.

\section{ACKNOWLEDGMENT}

This work was supported from funds NASA made available through the Engineering Research Institute, Iowa State University. I would also like to acknowledge the help of $\mathrm{J}$ : L. Steger with the programming of variable eddy viscosity and Susan Ray for computer run assistance. 


\section{REFERENCES}

1. Ciffone, D. and Orloff, K., "Far Field Wake Vortex Characteristics of Wings," AIAA Paper 74-505, 1974.

2. Rossow, V. J., "On the Inviscid Rolled-up Structure of Lift-Generated Vortices," J. Alrcraft, 10, 647-650, 1973.

3. Donaldson, C. DuP., Snedeker, R. S., and R. D. Sullivan, "A Method of Calculating Aircraft Wake Velocity Profiles and Comparison with Ful1-Scale Measurements," AIAA Paper 74-39, 1974.

4. Kamke, E., "Differential Gleichungen, Losungensmethoden Und Loesungen, Band 1, Equation 2.110, Chelsea, N.Y., 1948.

5. Rossow, V. J., "Prediction of Span Loading from Measured Wake-Vortex Structure - An Inverse Betz Method," to be published, AIAA Journal.

6. Kirde, K., "Untersuchungen uber die zeitliche Weilerenlwicklung eines Wirbeis mit vorgegebener Anfangsverteilung," Ingenieur-Archiv, 31 , $385-404,1962$.

7. Iversen, J. D., "Correlation of Turbulent Trailing Vortex Decay Data," to be published, J. Aircraft.

8. Brown, C. E., "Aerodynamics of Wake Vortices," AIAA Journal, 11, $531-536,1973$.

9. McCormick, B. W., Tangler, J. L., and Sherrieb, H., "Structure of Trailing Vortices," J. Aircraft, $\underline{5}, 260-267,1968$. 


\section{APPENDIX}

In order to match the variable eddy viscosity profiles with experiment, It will be necessary to adjust coefficients used in the calculation of initial profiles. For elliptic loading, the relationship ${ }^{2}$ between circulation $\widetilde{\gamma}$ and independent variable $\mathrm{N}$ is

$$
N=k_{1}\left\{\left[\frac{\pi}{4}-\frac{1}{2} \sin ^{-1} \sqrt{1-\widetilde{Y}^{2}}\right] / \widetilde{Y}-\frac{1}{2} \sqrt{1-\widetilde{Y}^{2}}\right\}
$$

where

$$
\begin{aligned}
& \mathrm{r} / \mathrm{b}=\sqrt{\frac{1}{4 \mathrm{~K}_{1}}} \sqrt{\mathrm{NT}} \\
& \mathrm{Vb} / \Gamma_{0}=\left(\sqrt{\mathrm{K}_{1}} / \pi\right) \tilde{\psi} / \sqrt{\mathrm{N} \tau} \\
& a \sqrt{\frac{\Gamma_{0}}{\mathrm{U}_{\infty} \mathrm{b}} \frac{\mathrm{x}_{o}}{\mathrm{~b}}}=\sqrt{\frac{\pi}{8 \mathrm{~K}_{1}}}
\end{aligned}
$$

the initial core size will also need to be adjusted. For triangular loading

$$
\begin{aligned}
& \mathrm{N}=\mathrm{K}_{2} \widetilde{\gamma}^{2} \quad(\mathrm{r} / \mathrm{b} \leq 0.25) \\
& \mathrm{r} / \mathrm{b}=\left(1 / 4 \sqrt{\mathrm{K}_{2}}\right) \sqrt{\mathrm{N} \tau} \\
& \mathrm{Vb} / \Gamma_{0}=\left(2 \sqrt{\mathrm{K}_{2}} / \pi\right) \tilde{\gamma} / \sqrt{\mathrm{N} \tau} \\
& \sqrt[\alpha]{\frac{\Gamma_{0}}{\mathrm{U}_{\infty} \mathrm{b}} \frac{\mathrm{x}_{0}}{\mathrm{~b}}}=\sqrt{\pi / 32 \mathrm{~K}_{2}}
\end{aligned}
$$

the values of $K_{1}$ and $K_{2}$ used in the examples were 755 and 3.4346 respectively. 